\title{
Backtable ventricular and atrial septal defect repair of an Eisenmenger allograft with concomitant domino heart transplantation
}

M. Gorlitzer, MD, ${ }^{a}$ H. J. Ankersmit, MD, ${ }^{a}$ G. Wollenek, MD, ${ }^{a}$ W. Wisser, MD, ${ }^{a}$ G. Wieselthaler, MD, ${ }^{a}$ M. Haisjackl, ${ }^{b}$ R. Horvat, MD, ${ }^{c}$ H. Gabriel, MD, ${ }^{d}$ E. Wolner, MD, ${ }^{a}$ and M. Grimm, MD, ${ }^{a}$ Vienna, Austria

From the Departments of CT Surgery, ${ }^{\mathrm{a}}$ Anaesthesiology, ${ }^{\mathrm{b}}$ Pathology, ${ }^{\mathrm{c}}$ and Internal Medicine, ${ }^{\mathrm{d}}$ General Hospital Vienna, Vienna, Austria.

Received for publication July, 18, 2001; accepted for publication July 25, 2001.

Address for reprints: Michael Gorlitzer, MD, Department of CT Surgery, General Hospital Vienna, Währinger Gürtel 18-20, 1090 Vienna, Austria (Email: michael.gorlitzer@ hotmail.com).

J Thorac Cardiovasc Surg 2002;123:374-6

Copyright $\odot 2002$ by The American Association for Thoracic Surgery

0022-5223/2002 $\$ 35.00+0 \quad \mathbf{1 2 / 5 4 / 1 1 9 0 6 2}$

doi:10.1067/mtc.2002.119062

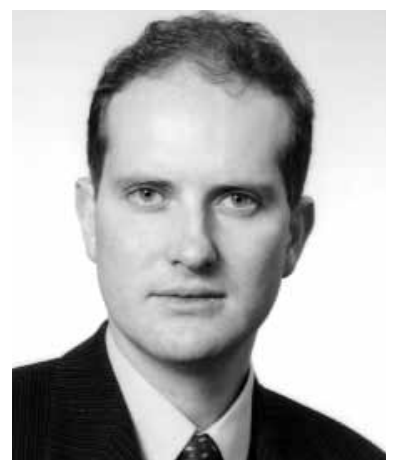

A llograft scarcity limits the clinical application of allograft transplantation. Domino heart transplantation has been described as a feasible option in acquiring additional heart allografts. ${ }^{1}$ New descriptive operative techniques and options in widening the donor pool are, however, limited in the recent literature. We are presenting the case of a patient who had pulmonary hypertension because of uncorrected persistent atrial and ventricular septal defects (ASD, VSD) and therefore was not suitable for primary heart transplantation. This patient underwent combined heart-lung transplantation after 11 months on the waiting list. The autochthonous heart with the ASD and VSD was replaced, surgically repaired in a backtable maneuver, and transplanted into a patient in New York Heart Association class IV. 
Yacoub and others demonstrated in their transplant programs that domino cardiac transplantation is a successful and feasible option for acquiring additional allografts with results comparable to those of conventional allotransplantation. ${ }^{2-4}$ In domino cardiac transplantation, usually the normal heart of a heart-lung transplant recipient is implanted into another recipient with end-stage heart failure. In addition to this previously described surgical scenario, we are reporting that an allograft that caused the Eisenmenger syndrome in the heart-lung recipient was repaired in a backtable procedure and successfully implanted as an allograft. A pathophysiological discussion is also included.

\section{Clinical Summary}

HEART-LUNG RECIPIENT. A 48-year-old woman with severe pulmonary hypertension resulting from a perimembranous VSD (18 $\mathrm{mm}$ in diameter) and a persistent oval foramen with Eisenmenger syndrome was evaluated for heart-lung transplantation. The cardiac disease had been diagnosed at 27 years of age. The symptoms became severe 1 year before transplantation (New York Heart Association class III-IV). Right heart catheterization revealed a mean pulmonary artery pressure of $76 \mathrm{~mm} \mathrm{Hg}$, a systemic cardiac output of $4.6 \mathrm{~L} / \mathrm{min}$, and a systemic flow index of $2.5 \mathrm{~L} \cdot \mathrm{min}^{-1} \cdot \mathrm{m}^{-2}$. The pulmonary flow rate was $2.3 \mathrm{~L} / \mathrm{min}$ with an index of $1.3 \mathrm{~L}$. $\mathrm{min}^{-1} \cdot \mathrm{m}^{-2}$. The total pulmonary resistance was 2652.4 dynes $\cdot \mathrm{s}$. $\mathrm{cm}$. The total lung capacity was $4.44 \mathrm{~L}(76 \%)$ and the vital capacity was $2.71 \mathrm{~L}(65 \%)\left(\mathrm{PaO}_{2} 32 \mathrm{~mm} \mathrm{Hg}, \mathrm{PaCO}_{2} 41 \mathrm{~mm} \mathrm{Hg}\right)$. In November 2000, after an 11-month waiting period, organs from a suitable donor became available. After donor-recipient matching, including identical blood group, negative direct crossmatch, and appropriate lung size, combined heart-lung transplantation was performed.

HeArt RECIPIENT. A 63-year-old man presented in 1994 and 1996, 6 and 4 years before this operation, with severe coronary artery disease and myocardial infarction. Cardiology interventionalist therapeutic modalities in this patient were dilatation (percutaneous transluminal coronary angioplasty) of the left anterior descending coronary artery in 1994 and stent implantation in 1996. The patient also had a history of cardiac decompensation necessitating multiple hospitalizations. Three months before the operation, cardiac decompensation again developed, making inotropic support necessary. After recompensation, an echocardiogram verified an ejection fraction of $10 \%$, cardiac catheterization showed a mean pulmonary pressure of $37 \mathrm{~mm} \mathrm{Hg}$, and the pulmonary vascular resistance was estimated to be 3.9 Wood units. In view of his severe symptoms the patient was placed on the heart transplant waiting list. A suitable donor for this recipient was found in our aforementioned patient with severe fixed pulmonary hypertension resulting from congenital Eisenmenger syndrome.

The domino heart was excised after cardioplegic arrest (cold blood cardioplegia) with an adequate length of superior vena cava to preserve the sinoatrial node. In a backtable procedure, the perimembranous VSD was closed with a Dacron patch by a simple suture technique. The ASD was closed primarily with a partial purse-string suture. The transplantation procedure was performed in an operating theater adjacent to the room in which the heart-lung transplantation was done. Cold blood cardioplegia was administered every 15 minutes during implantation of the allograft, and the operation was technically uneventful. Postoperative transesophageal echocardiography showed satisfactory pump function

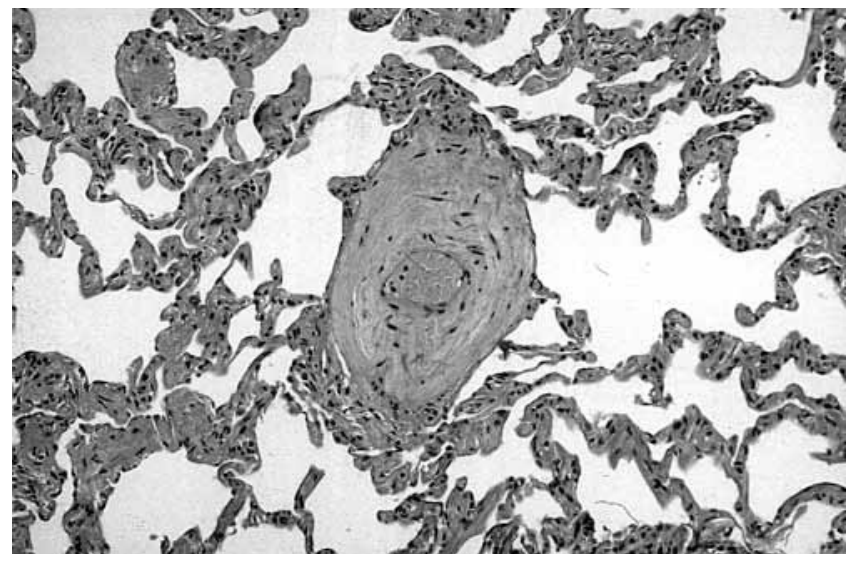

Figure 1. One paraffin section of lung parenchyma showing a severe pulmonary arterial lesion (Heath-Edwards grade 4 pulmonary hypertension). Significant occlusive intimal fibrosis is apparent. (Hematoxylin and eosin stain; original magnification $\times 100$.)

although atrial pacing was needed for 24 hours. Because of delayed awakening, a cerebral computed tomographic scan was performed, showing an area of chronic ischemia in the distribution of the left posterior and right medial cerebral arteries. Seven days after transplantation, however, the patient was awake with no signs of neurologic deficits.

The immunosuppressive protocol consisted of a 5-day course of antithymocyte immunoglobulin $(2 \mathrm{mg} / \mathrm{kg})$ followed by triple therapy with corticosteroids, azathioprine, and cyclosporine (150$220 \mathrm{ng}$ ). Three weeks after transplantation the patient had a seizure, which was considered to be a side effect of increased cyclosporine levels. The patient was successfully treated with phenytoin, and the calcineurin inhibitor cyclosporine was switched to FK506. Routine cardiac biopsies performed 7, 14, 21, and 30 days after transplantation confirmed no allograft rejection (International Society for Heart and Lung Transplantation [ISHLT] grade 0 -I). Two months after transplantation, the patient was rehospitalized because of weakness and debility resulting from hypovolemia. Results of a cardiac biopsy showed no rejection and the echocardiogram demonstrated normal right and left ventricular function (ejection fraction 63\%). In the subsequent 4 months of early convalescence, the recovery was uneventful.

\section{Discussion}

VSD occurs in 1 of 1000 live births, ${ }^{5}$ and ASD is present in $10 \%$ to $15 \%$ of patients with congenital heart disease. ${ }^{6}$ If not corrected, Eisenmenger syndrome develops. The pathophysiology of this disease is determined by size of the defects and the pulmonary vascular resistance and is influenced by the pressure gradient and shunt volume across the defects. In our patient the right ventricular systolic pressure nearly equaled the left ventricular pressure, and a large increase in pulmonary blood flow occurred. This led to a rearrangement of the pulmonary vascular bed, as seen in Figure 1. The histologic severity, as described by Heath and Edwards, ${ }^{7}$ was grade IV; it was positively correlated with the pulmonary vascular resistance and inversely related to the magnitude of shunting 


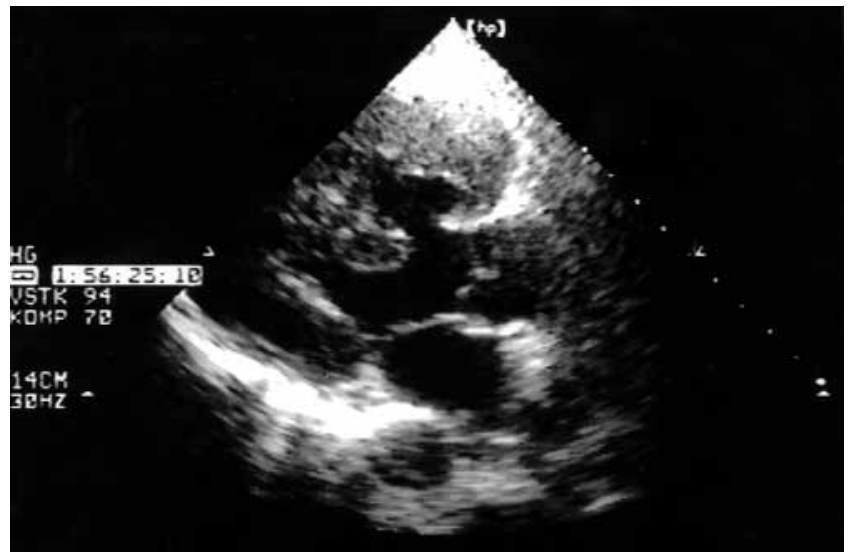

Figure 2. Two-dimensional echocardiographic visualization of the Eisenmenger heart with a clearly demonstrated perimembranous VSD. Note the massive hypertrophy of the right ventricle and septum.

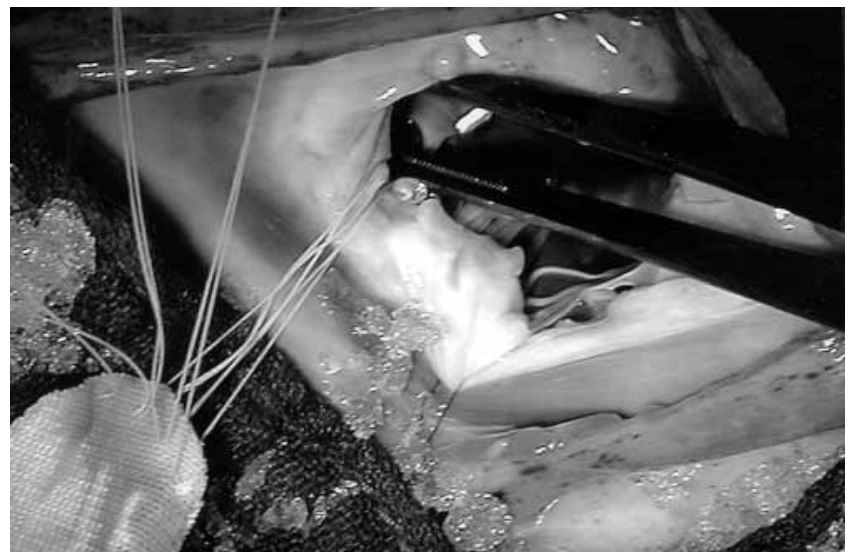

Figure 3. Backtable repair of the VSD with implantation of a Dacron patch. at the ventricular level. Moreover, right ventricular hypertrophy was noted in a 4-chamber 2-dimensional echocardiogram (Figure 2 ). This defect was diagnosed at age 26 years (maladie de Roger) when the patient first began having symptoms. Operative closure was deemed impossible because of expected right heart failure resulting from hypertensive pulmonary vascular disease and increased Wood units. Therefore, combined heart-lung transplantation was believed to be the only curative option. A histologic Heath-Edwards grade greater than 3 is unlikely to be associated with reversibility of hypertensive pulmonary vascular disease, irrespective of disease genesis (for example, long-lasting ischemic or idiopathic cardiomyopathy with left heart failure and consequent pulmonary congestion or ASD and VSD). We mention this particular histopathophysiologic finding because histologic pulmonary rearrangements are ultimately responsible for increased pulmonary wedge pressure (Wood units $>4$ ) and are deemed in our institution to be relative contraindications to heart transplantation. ${ }^{8}$ With this in mind, prior risk adjustments are performed in our unit in patients who are transplant candidates. In diverse highand low-risk patients, drugs such as dinoprostone [prostaglandin $\left.E_{2}\right]^{9}$ or nitric oxide are used. One might speculate that this clinical finding is correlated with the Heath-Edwards histologic grading. However, clinical studies are warranted.

In conclusion, (1) heart-lung transplantation for cystic fibrosis and subsequent domino heart transplantation in patients with New York Heart Association class IV disease has excellent results, as was verified by our good result in a patient with Eisenmenger syndrome, and (2) the backtable maneuver is, to the best of our knowledge, the first description of creating an additional allograft (Figure 3). A highlight of this procedure is that the "living" donor allows improved prospective evaluation, such as echocardiography, cardiac catheterization, prospective leukocyte antigen matching and, more important, avoidance of changes of deleterious plasma hormone levels that develop in brain-dead patients. ${ }^{10}$ In this particular clinical scenario, the good clinical outcome of our 2 patients allows us to propose this innovative use of a repaired Eisenmenger allograft and concomitant domino heart transplantation.

\section{References}

1. Sutor S, Wieczorek P, DeMaio K, Gibson J, Michael K, Riddleberger S. Dominio transplants: sequential heart and heart-lung transplantation. AORN J. 1988;48:876-89.

2. Yacoub MH, Banner NR, Khaghani A, Fitzgerald M, Madden B, Tsang V, et al. Heart-lung transplantation for cystic fibrosis and subsequent domino heart transplantation. J Heart Transplant. 1990;9: 459-67.

3. Klepetko W, Wollenek G, Laczkovicx A, Laufer G, Wolner E. Domino transplantation of heart-lung and heart: an approach to overcome the scarcity of donor organs. J Heart Lung Transplant. 1991;10:129-31.

4. Baumgartner WA, Traill TA, Cameron DE, Fonger JD, Birenbaum BA. Unique aspects of heart and lung transplantation exhibited in "domino-donor" operation. JAMA. 1989;261:3121-5.

5. Tchervenkow CI, Shum Tim D. Ventricular septal defect. In: Baue AE, editor. Glenn thoracic and cardiovascular surgery. Old Tappan (NJ): Appleton \& Lange; 1996. p. 1127.

6. Hamilton WI, Haffaja CI, Dalen JE, Dexter L, Nadas AS. Atrial septal defect secundum: clinical profile with physiologic correlates in children and adults. Cardiovasc Clin. 1979;10:267-77.

7. Heath D, Edwards JE. The pathology of hypertensive pulmonary vascular disease: a description of six grades of structural changes in the pulmonary artery with reference to congenital defects. Circulation. $1958 ; 18: 533$

8. Zuckermann AO, Ofner P, Holzinger C, Grimm M, Mallinger R, Laufer G, et al. Pre- and early postoperative risk factors for death after cardiac transplantation: a single center analysis. Transpl Int. 2000; 13:28-34.

9. Hulsmann M, Stefanelli T, Berger G, Sturm B, Parkner A, Zuckermann A, et al. Response of right ventricular function to prostaglandin $\mathrm{E}_{1}$ infusion predicts outcome for severe chronic heart failure patients awaiting urgent transplantation. J Heart Lung Transplant. 2000;19:939-45.

10. Wilhelm MJ, Pratschke J, Beato F, Tall M, Kusaka M, Hancock WW, et al. Activation of the heart by donor brain death accelerates acute rejection after transplantation. Circulation. 2000;102:2426-33. 